\title{
HJALMAR STOLPE - EN FOLKBILDARES UTSTÄLLNINGSSYN
}

\section{Claes Hallgren}

Hjalmar Stolpe är mest känd i Sverige som arkeolog och då främst för sina arkeologiska grävningar och undersökningar i Birka. Hans roll som etnograf och etnografisk utställare är mindre känd. Denna gärning kan i sin tur delas upp, eftersom Stolpe å ena sidan var en internationellt känd forskare genom sina teoretiska skrifter om ornamentikens utveckling, medan han å andra sidan som utställare främst hade ambitionen att sprida etnografisk kunskap till en bred allmänhet. Den sistnämnda rollen, som kommer att uppmärksammas här, är kanske den minst kända.

Hjalmar Stolpe (1841-1905) började sin vetenskapliga bana som naturhistoriker men övergick så småningom till att bli arkeolog och etnograf. Som arkeolog blev han först känd genom sina utgrävningar på Björkö (1872-1879,1881) och sin bearbetning av detta material, men han var även involverad i andra arkeologiska utgrävningar, som de av gravfältet i Vendel och utforskandet av grottorna på Stora Karlsö, Gotland.

Stolpe medverkade till grundandet av Antropologiskt Sällskap 1873 (från 1877 ombildat till Svenska Sällskapet för Antropologi och Geografi) där han var sekreterare för den antropologiska sektionen mellan 1877 och 1879 samt ledamot av styrelsen från 1895 till sin död. På sällskapets initiativ utsågs Stolpe till ansvarig för arrangerandet av den «Allmänna etno- grafiska utställningen» i Stockholm 187879 i Arffurstens Palats. Med hjälp av ett stipendium studerade han 1880-81 utställningar och föremål i etnografiska museer och privatsamlingar i Europa (resan följdes av flera för studier i Europa). Áren 1883-1885 medföljde han som etnograf fregatten Vanadis på en jordenrunt expedition med uppgift att hemföra etnografiska samlingar till ett svenskt etnografiskt museum. I Calcutta lämnade han expeditionen 1885 och fortsatte resan hem på egen hand efter en vistelse i Norra Indien som han ägnade åt att samla och dokumentera etnografiska föremål. Expeditionens etnografiska resultat förevisade Stolpe genom två «Vanadisutställningar» i Stockholm och Göteborg 1886 och 1887. Ar 1900 utsågs han till föreståndare för Riksmuseets Etnografiska Afdelning, som 
88 då bildades som en särskild enhet inom Riksmuseet (där etnografin tidigare ingått i avdelningen för ryggradsdjur). År 1903 utnämndes han till intendent och professor vid denna avdelning.

Stolpe var dessutom medlem i andra vetenskapliga sammanslutningar och medverkade i åtskilliga svenska och internationella kongresser. Hans verksamhet och karriär präglades i hög grad av hans strävan att upprätta ett etnografiskt museum och att främja etnografin som vetenskap (Retzius 1905. Du Rietz 1984).

Etnografiska museer har sedan Stolpes tid haft en folkbildande uppgift och det senaste decenniet har denna roll varit i centrum för en intensiv uppmärksamhet inom antropologin och andra ämnen, som studerat hur "andra folk» presenterats eller presenteras i en västerländsk kontext. Detta har skapat en medvetenhet om de västerländska föreställningar och teoretiska premisser som ligger bakom etnografiska utställningar. När det gäller etnografiska utställningar under Stolpes tid i slutet av 1800-talet och början av 1900-talet finns det naturligtvis ett samband mellan etnografiska utställningar och de antropologiska teorier, som var aktuella under denna tid. I Stolpes fall innebar emellertid inte detta att den teoretiska ståndpunkt som han pläderade för i sina studier om ornamentiken också var vägledande för hans utställningsverksamhet. Detta var inte specifikt för Stolpe, utan en jämförelse mellan honom och andra samtida antropologer och utställare, främst Franz Boas, visar att det inte finns något enkelt eller självklart samband mellan deras utställningsfilosofi och de teoretiska inriktningar de förespråkade $\mathrm{i}$ andra sammanhang.
Antropologisk teori lät sig då, som nu, inte översättas i utställningsform utan problem och Stolpes fall illustrerar en fràgeställning som fortfarande är aktuell. Hur förhåller sig etnografiska utställningar till antropologisk teoribildning?

\section{STOLPES TEORI OM ORNA- MENTIKENS UTVECKLING}

Stolpes gärning som folkbildare var således intimt förknippad med hans roll som utställare - inkluderande de katalogtexter han skrev i samband med utställningar men inom etnografin blev han i första hand känd för sin teori om ornamentikens utveckling. Utanför Sverige uppmärksammades denna främst av brittiska antropologer verksamma inom samma ämnesområde. Flera av dem läste till och med hans artiklar på svenska innan de översattes till engelska.

Stolpe presenterade sina idéer inom ornamentiken först i två artiklar i tidskriften Ymer med titeln, Utvecklingsföreteelser $i$ naturfolkens ornamentik. Den första publicerades 1890 och den andra med samma titel (men markerad som II) $1891^{1}$.

I dessa första artiklar från 1890 och 1891 använder Stolpe etnografiska exempel från Herveyöarna i Oceanien. Valet av denna ögrupp hade inte bara att göra med att Stolpe här fann en ornamentik som intresserade honom, utan också på dess geografiska belägenhet. Den oceanska övärlden var lämplig för studier av naturfolkens ornamentik, menade Stolpe, på grund av öarnas relativa isolering från varandra. Här kunde ornamentiken utvecklas utan yttre påverkan så att varje folks "egendomliga och karakteristiska» stil 
framträdde (1890a:195). När väl en specifik stil definierats, menade Stolpe att det ständiga återupprepandet av vissa detaljer som var «af ringa värde såsom prydnad betraktad» tydde på att en "djupare orsak» låg bakom denna regelbundenhet (Ibid:199). För att kunna förklara denna regelbundenhet använder han sig av den darwinistiska utvecklingsläran:

Utvecklingsläran, som verkat befruktande på så många olikartade vetenskaper, finner äfven inom denna del af etnografien sin rika tillämpning. Vid studiet af ett stort ornamentmaterial finner man ofta, att vissa, vid första påseendet obetydliga detaljer genom en serie af mellanformer låta förklara sig såsom rudiment af andra, från den organiska naturen hemtade förebilder. Rudimenten kunna vara mer eller mindre tydliga, de hafva dock alltid till uppgift att föreställa och i minnet återkalla den bild, från hvilken de leda sitt ursprung. (Stolpe 1890a:199)

Stolpes arbete går sedan ut på att härleda och i text och bild visa hur ornament från att ha varit realistiska avbildningar av människor eller djur alltmer stiliseras för att ge upphov till de till synes abstrakta former som så småningom uppstår. För Stolpe var det viktigt att fastställa att det verkligen rörde sig om påvisbara verkliga samband eller, som han kallar det, "genetiska samband», och i darwinistisk anda använder han uttryck som «felande länk» när han försöker fastställa mellanformer $\mathrm{i}$ en serie.

I motsats till förespråkare för associativa stiliseringsprocesser, där den ursprungliga bilden förvanskas till oigenkännlighet, förankrar Stolpe sin teori i en specifik geografisk och religiös kontext, vilket innebar att den ursprungliga bilden och dess inne- börd kan igenkännas av det berörda folket. Han uppmärksammar och beskriver därför utförligt den mytologiska religiösa värld, som ornamentiken kan härledas till hos ett visst folk. En sådan kontextualisering skulle idag kunna uppfattas som att Stolpe insisterade på en kulturspecifik utveckling av ornamentiken, där en allmän och objektiv lagbundenhet är utesluten. Men Stolpe såg tvärtom ornamentikens utveckling i direkta biologiska termer:

To Biological Science belongs the task of ascertaining the origin and the meaning of an ornament as well as the history of its evolution, which is controlled by laws as fixed as those that govern the evolution of animals; and thus briefly indicated, they are in action over the whole world. It is indeed a singular spectacle to behold their operation in all nations and in all times, among savages of the lowest type as well as among the most highly cultured communities. Evolution pursues everywhere a course that is immutable, no matter what changes take place in the passive material. (Stolpe 1896,1927:70)

Formen för en sådan lagbunden utveckling inom ornamentiken kunde påminna om de bilder som, ofta i karikatyrform, utmålade stegen från apa till människa, även om Stolpe som seriös vetenskapsman avvisade sådana som just karikatyrer.

Genom att Stolpe begränsade denna utvecklingsprocess till ett specifikt folk skilde sig hans teori från den dominerande skolan inom brittisk antropologi under slutet av 1800-talet och början av 1900talet, som saknade en sådan regional förankring. Inspirerad av både äldre evolutionistiska och darwinistiska idéer, försökte teoretiker inom denna skolbildning skapa evolutionistiska samband baserade på 
likheter mellan skilda folk. Olika samhällen jämfördes utifrån kriterier som religion, giftermål, lagar och andra sedvänjor, som ordnades $\mathrm{i}$ en evolutionistisk skala där den västerländska formen betraktades som den mest utvecklade. Även i detta fall sågs utvecklingen som lagbunden, men i ett vidare perspektiv där seder och bruk hos vitt skilda folk jämfördes. Stolpe däremot såg utvecklingen av ornamentiken som «karakteristisk» och "egendomlig» för ett visst folk.

Stolpes regionalt förankrade utvecklingsmodell hade en svensk bakgrund. Hans idéer inom ornamentiken var direkt inspirerade av svenska arkeologiska teoretiker. Han nämner själv Hans Hildebrand och Oscar Montelius, vars typologiska undersökningar inom arkeologin riktade Stolpes uppmärksamhet "på likartade företeelser hos naturfolken» (Stolpe 1891:222). Sven Nilsson bör också nämnas i detta sammanhang. Alla tre blev internationellt erkända auktoriteter inom arkeologin. Det här är inte platsen att exakt utreda hur Stolpes idéer var relaterade till var och en av dessa, men det är ändå uppenbart att särskilt Montelius bidrag till den arkeologiska forskningen måste ha spelat en stor roll för Stolpes idéer inom ornamentiken.

Montelius (Trigger 1989:155-161) var liksom de andra nämnda arkeologerna delaktig i utvecklandet av den moderna arkeologi som förknippas med indelningen i sten-, brons- och järnålder, som inletts av danska arkeologer. Precis som Stolpe utgick Montelius från darwinismen och såg en ändrad utformning av vissa arkeologiska föremål, som stenyxor, i termer av en logisk lagbunden utveckling, direkt jämförbar med den som skedde hos biologiska organismer. Montelius verkligt innovativa bidrag till arkeologin var emellertid en förfining av den typologiska metod som initierats av danskarna. Han menade att en klassificering i så vida begrepp som sten-, brons- och järnålder, måste kompletteras med mindre enheter, bestämda utifrån likheter i form och dekoration på föremål, som representerade perioder omfattande kanske några hundra år. I samband med detta noterade han regionala variationer och historisk påverkan. Denna inriktning ledde till att Montelius också utvecklade en diffusionistisk teori för spridningen av förhistorisk teknologi i Europa, men för den här diskussionen är det viktiga att han betonade betydelsen av regionala enheter i förhistoriska sammanhang. För Montelius speglade föremålen regionala särdrag, på samma sätt som etnografiska föremål för Stolpe speglade vad han ofta kallade "karakteristiska kulturegendomligheter». Stolpe använde även detta eller liknande uttryck när han skrev i arkeologiska ämnen, som när han $\mathrm{i}$ en artikel talar om gravskickens "karakteristiska egendomligheter» i samband med Tuna-fynden från Alsike i Uppland (Stolpe 1895b:219).

Eftersom Montelius var den som aktualiserade arkeologiska studier av regionala enheter inom ramen för en $i$ grunden evolutionistisk syn, är det högst sannolikt att Stolpes regionala utgångspunkt för ornamentikens utveckling inspirerades av denne.

Det fanns ytterligare en svensk bakgrund till att Stolpe avvisade alla tankar på samband mellan olika folk baserade på likheter $\mathrm{i}$ deras ornamentik för att istället inskränka sig till utvecklingsserier hos ett visst folk.

I Sverige hade under 1600-talet en teori 
som utgick från ytliga likheter mellan företeelser hos olika folk presenterats av Olof Rudbeck. Svenska ortnamn och andra svenska ord sågs som varianter av någorlunda likalydande ortnamn och ord tagna ur den grekiska historien och mytologin, med slutsatsen att Sverige varit det Atlantis, som beskrivits av Platon. Rudbecks fantastiska tolkningar i denna genre hade skapat ett sådant vanrykte för samband byggda på ytliga likheter, att de som senare betecknade sig själva som seriösa vetenskapsmän i Sverige aktade sig för denna typ av jämförelser. Atminstone gällde detta Stolpe som i några fall gick till rätta med utländska vetenskapsmän som låg farligt nära det Rudbeckska exemplet. ${ }^{2}$

Ett sådant fall redovisar Stolpe i en artikel där han redogör för sina intryck av museer i Europa, som han besökte under studieresan 1880-81. Det gäller en utställning anordnad av Pitt-Rivers i London. Pitt-Rivers överförde senare sin samling till ett eget etnografiskt museum i Oxford, Pitt-Rivers-museet, men redan vid Stolpes utställningsbesök var principen för det framtida museets utställningsinriktning utarbetad. Utställningen var typologiskt ordnad för att spegla utvecklingen av form och funktion hos olika föremål. Trots att Pitt-Rivers liksom Stolpe kombinerade antropologi och arkeologi utifrån ett utpräglat darwinistiskt utvecklingsperspektiv, fick hans utställning Stolpe att associera till Rudbecks diffusionism:

Meningen synes vara att visa typernas utveckling, dock ej hos ett visst folk, utan hos menskligheten i dess helhet. Detta sker genom att till en grupp sammanföra alla föremål af samma form och bestämmelse, utan hänsyn till deras olika härkomst /.../ Inom hvarje grupp ordnas föremålen i serier, som skola representera utvecklingen. På detta sätt komma, bland annat, bågar från Brasilien, Fidji-öarna, återigen Brasilien, Nya Guinea etc. etc. om hvarandra, allt eftersom de visa någon liten tillfällig likhet i form, som gör att de kunna betraktas som öfvergångsformer i serien. Sin höjdpunkt når denna konfusion, då uppmärksamheten tillika fästes derpå, att båge «i Brasilien» (på hvilket af de många indianspråken, säges ej) heter "Gura Para» och "Vira Para" och i Polynesien «Pana», samt pil på Samoa-öarna "U", på Nya Hebriderna "Us" och i Brasilien «Uba». Likartade exempel skulle kunna anföras från alla de öfriga grupperna af klubbor, spjut, metkrokar, prydnader etc., men utrymmet medger det ej. Tendensen är emellertid klar. I Sverige brukar man kalla sådant "Rudbeckianism», och hela arrangemanget i Pitt Rivers samling ser ut som en illustration dertill. (Stolpe 1882:16-17)

\section{TYPOLOGISKT OCH GEOGRAFISKT ORDNADE UTSTÄLLNINGAR}

Intrycket av Pitt-Rivers utställning var emellertid inte helt negativt, eftersom det fanns exempel på geografiskt avgränsade serier i Pitt-Rivers typologi. Sådana var, skriver Stolpe, "lika instruktiva, som alla de andra vilseledande.» Och han tillägger «Hvarje museum bör sträfva att anlägga sådana etnografiskt begränsade typserier. De utgöra vetenskapens hörnstenar.» Det ligger nära till hands att tro att Stolpe följde sin egen rekommendation och förevisade sådana typserier i Stockholmsmuseet. I den relativt utförliga dokumentation av dessa utställningar - huvudsakligen presenterade av honom själv i text, (men en hel del fotografier finns också bevarade) finns det emellertid få tecken på att Stolpe följde detta råd. Ett exempel finns dock i en presentation av museets utställningar som han skrev om i tidskriften Hvar 8 
92 Dag 1903, där han anger att en utställning, med föremål från Hervey-öarna (dvs. det etnografiska material som han främst utgick från i sin skrivna analys av ornamentiken) illustrerar uppkomsten av en geometrisk ornamentik. Föremålen gav "det tydligaste och mest instruktiva af alla exempel på en rent geometrisk ornamentiks uppkomst genom stilisering af en otalig mängd ursprungligen realistiskt återgifna människofigurer, de såsom gudar dyrkade förfäderna» (Stolpe1903:457).

Ytterligare ett exempel på en typologisk utställning i museet, finns dokumenterad i en utställningskatalog skriven av Erland Nordenskiöld 1907, två år efter Stolpes död. I Nordenskiölds presentation av samlingarna, ges Stolpes typologi emellertid en mycket blygsam plats. I en utförlig beskrivning av föremålen på 35 sidor, så nämns bara mycket kortfattat ett enda exempel som avser att illustrera Stolpes teori. Det gäller klubbor från Guyana och Venezuela, om vilka katalogförfattaren skriver

Klubbor ur äldre samlingar. Meningen är att visa Stolpes studier öfver de antropomorfa ornamentens utveckling på dessa. (Nordenskiöld 1907:23).

Även om andra exempel kan ha funnits är det uppenbart att typologiska utställningsinslag var marginella. ${ }^{3}$ Den utställningsmetod Stolpe istället valde, och som han utförligt motiverar i sina artiklar och katalogtexter, var geografiskt arrangerad.

De typologiska och geografiska utställningsmodellerna var de två huvudsakliga alternativen under Stolpes tid, och för att förstå hur en typologiskt orienterad teoretiker kom att välja den geografiska modellen är det nödvändigt att först ge en all- män presentation av de båda alternativen.

Det som generellt kännetecknade typologiska utställningar var att man relaterade föremål till varandra med utgångspunkt från funktion och form. Både diffusionistiska och evolutionistiska samband kunde skapas genom att på denna grund sammanföra föremål från skilda geografiska områden, men under Stolpes tid kom den framför allt att förknippas med en evolutionistisk syn. Den implicita slutpunkten på en evolutionistisk skala var de avancerade föremål som förekom i västerländska samhällen. Ett spjut kunde exempelvis ses som början på en utveckling som slutade med ett gevär, även om gevär inte var utställda. Pitt-Rivers-museet, var typologiskt ordnat, men som framkommit förekom också geografiska begränsningar inom ramen för denna ordning. En sådan blandning av typologiska och geografiska arrangemang var inte helt ovanlig (Chapman 1985:16). Jomard, en av grundarna till det etnografiska museet i Paris, hade från 1828 hand om «kuriosa» och "exotiska föremål» $\mathrm{i}$ ett bibliotek i Paris och föreslog där ett aldrig genomfört etnografiskt klassifikationssystem med indelning i «ordres», «espèces» och "variétés». I detta rymdes kategorier som mat, kläder, byggnadsmaterial, jordbruksredskap, vapen, men också ett geografiskt kriterium, även om det kom i sista hand (Chapman 1985:25).

Jomards modell ifrågasattes av Philip von Siebold i Leiden, som menade att ett system som i första hand utgick från geografiska bestämningar («racial and cultural groupings») på ett bättre sätt skulle spegla de olika folkens relativa framsteg dvs. det rörde sig om en evolutionistisk vision som var geografiskt ordnad (Chapman 1985:24). Mellan Jomard och Siebold 
uppstod under förra delen av 1800-talet en debatt om de två olika systemens förtjänster (Jacknis 1985:79-80). Frågeställningen var således inte ny för Stolpes tid, men de båda utställningsformerna behövde inte ställas mot varandra utifrån ett evolutionistiskt perspektiv. Geografiska principer kunde bakas in i typologiska utställningar och geografiska utställningar kunde utformas enligt evolutionistiska principer.

Den geografiska indelningen föreslog sig naturligtvis själv, i viss mån, med tanke på tidens sätt att ordna jordens befolkning efter ras, grupp, stam, folk eller nation. Men detta innebar inte att den var oproblematisk ur teoretisk synpunkt, som debatten mellan Jomard och Siebold illustrerar. Den kunde illustrera olika infallsvinklar, även sådana som inte var evolutionistiska. Henry Christy, som vid 1800talets mitt byggde upp en etnografisk samling i England, baserade denna på en geografisk princip, men i motsats till Siebolds utställningsmodell, var den inspirerad av en diffusionistisk syn som präglade antropologin i England före det darwinistiska genombrottet (Stocking 1991:264).

Den som framför allt kom att förknippas med den geografiska utställningsmodellen, under slutet av 1800-talet och början av 1900-talet, var Franz Boas. Han skapade, efter att ha flyttat från Tyskland till USA, en antropologisk skolbildning där varje kulturs egenart framhävdes. Även om Boas utvecklade sitt teoretiska perspektiv i USA, så hade det sina rötter i en tysk antropologi, där begreppet "Volksgeist" hade skapats för att uttrycka en historiskt grundad särart hos ett visst folk. Inspirerad av denna tyska tradition kom Boas mycket tidigt i polemik med evolu- tionistiskt inriktade teoretiker i USA, när han förordade en geografisk utställningsmodell. Boas formulerade denna utställningsmodell i direkt opposition mot typologiskt ordnade evolutionistiska utställningar och $\mathrm{i}$ andra sammanhang kritiserade han Stolpes typologiskt inspirerade teori om ornamentikens utveckling (Boas 1927,1955:127-129). Trots att Stolpe liksom Boas förordade en geografisk utställningsmodell skilde de sig således $\mathrm{i}$ en grundläggande teoretisk fråga.

Vi ska återkomma till skillnader och likheter mellan Boas och Stolpes utställningsfilosofi, men tills vidare räcker det med att påpeka att en geografisk utställningsfilosofi inte var något entydigt koncept, som utan vidare kan sammankopplas med ett visst teoretiskt perspektiv. Stolpes geografiskt ordnade utställningsmodell kräver därför en närmare presentation.

\section{STOLPES GEOGRAFISKA UTST $̈ L L N I N G S M O D E L L$}

När Stolpe kritiserar Pitt-Rivers utställning för att sammanföra och jämföra föremål från vitt skilda områden utan hänsyn till deras "olika härkomst», tillfogar han, «Här är således ej fråga om något etnografiskt system» (Stolpe 1882:17). I utställningssammanhang upprepar han vid flera tillfällen vikten av en uetnografisk ordning», som klart anger härkomst och sammanför föremål från samma område. I samma artikel från 1882 motiveras utförligt varför en sådan ordning bör gälla på etnografiska museer:

Det är genom att noggrant jemföra alla föremål från ett visst folk, man kommer till insigt af det verkligt karakteristiska. Först sedan man kommit 
94 derhän, är man mogen att anställa jemförelser med andra folkalster. Ett etnografiskt museum har två huvuduppgifter att fylla, den ena att gifva material åt vetenskapliga studier, den andra att bilda den allmänhet, som i museet söker näring för sin vetgirighet. Är den etnografiska anordningen den enda, som kan tillfredsställa vetenskapsmannen, är den i ännu högre grad nödvändig för den icke fackbildade allmänheten. Den kommer ej till museet för att studera metkrokar eller klubbor, eller gräskjolar, den kommer för få lära något om folken. Vetenskapsmannen må för vissa syften i sina bearbetningar uppvisa paralleler emellan ett visst slags föremål hos vissa folk, men att bygga anordningen af ett museum på denna princip blifver vilseledande, derigenom att allmänheten förledes att tro på paralleler, der sådana icke finns. (Stolpe 1882:33-34)

Att tro på "paralleler, der sådana icke finns», var en varning, som berörde en av hörnstenarna i Stolpes teori om ornamentiken. Den riktade sig lika mycket mot en diffusionism, som såg sådana paralleller som ett tecken på kontakt, som mot en evolutionism som sammanförde enskilda fenomen och föremål från vitt skilda folk, på grundval av yttre likheter. Men eftersom ornamentiken inte berördes, eller berördes marginellt, i utställningar arrangerade av Stolpe, kom denna kritik av analogiska samband att här förknippas med hans egen geografiska utställningsmodell dvs. hans «etnografiska system» och få ett egenvärde i detta sammanhang.

Utställningar skulle i första hand "lära» allmänheten «något om folken». För att uppnå detta syfte ville Stolpe låta de utställda föremålen spegla en så heltäckande bild som möjligt av de olika folkens verksamhet och föreställningar. I en artikel skriven 1903 Hvad är och Hvad bör ett
Etnografiskt Museum Vara? redogör han utförligt för denna ståndpunkt:

..det är just de främmande folkslagens seder och bruk som ett etnografiskt museum vill åskådliggöra och rörande hvilka det också rätt ordnadt är i stånd att gifva en långt mera lefvande föreställning, än någon aldrig så rikligt illustrerad bok. Museet skall visa de olika folkens sätt att kläda och pryda sig, deras husgeråd och näringsämnen och sätten för dessas tillredande, det skall visa de redskap eller vapen, med hvilka människan gjort och gör den omgifvande naturen sig underdånig och de vapen med hvilka hon allt sedan Kains dagar sökt tillkämpa sig sin verkliga eller inbillade rätt, eller försvara sig mot sina fiender. I förfärdigandet af dessa vapen och verktyg, likasom också af alla andra nödvändighetsartiklar, har människan äfven på de mest primitiva stadier utvecklat ett sinne för såväl det ändamålsgivna som det prydliga, hvilken utveckling det ej kan vara annat än i hög grad väckande att närmare studera. Vidare skall ett etnografiskt museum visa de mera intellektuella sidorna af de olika folkens lif, från de lägre ståendes vidskepelse och trolldom, upp till de mera framskridnas mer eller mindre högt utvecklade religioner. (Stolpe 1903: 455)

Ambitionen att ge en så fullständig bild av ett folk som möjligt innefattade emellertid inte riktigt alla samhällslager. I begreppet «folk» låg en snävare innebörd, som Stolpe berör, när han i samma artikel nämner de japanska och indiska samlingarna, som härrör från Vanadisexpeditionen 18831885:

Den ledande tanken vid insamlandet af såväl det japanska, som det indiska och siamesiska materialet, var att visa huru det egentliga folket lefver. De högre, rikare klassernas lif måste lämnas utom räkningen, huvudsakligen på grund af det alltför knappa anslag som stod till Vanadisexpeditionens etno- 
grafs förfogande. Men «massan» av ett folk är ju också för etnografen den viktigaste att studera. Så godt medlen tillåtit visar därföre samlingen den japanska medelklassens lif, dess husgeråd och öfriga karaktäristiska tillhörigheter./.../ Rörande den indiska afdelningen gäller detsamma som om den japanska, det är genomsnittsfolket den egentligen vill illustrera. Födoämnen, husgeråd, dräkter, prydnader, musikinstrument, spel-utensilier etc. fylla den första salen, medan den andra är ägnad åt religionen eller rättare åt religionerna... (Ibid: 458)

De indiska föremål som Stolpe själv samlat och ställt ut, belyser också en annan aspekt av hans utställningsfilosofi. Under Vanadisexpeditionen, som hade formen av en världsomsegling, där syftet inte främst var etnografiska studier, valde Stolpe att lämna fartyget i Indien. Missnöjd med de alltför korta uppehållen på resan stannade han under en längre period i norra Indien för utförligare studier och insamling av föremål. Den indiska samlingen kom därför att i hög grad spegla Stolpes idé om hur en etnografisk samling skulle se ut. I en presentation av utställningarna publicerad 1895, betonar han liksom i artikeln från 1903, att föremålen avser att ge en heltäckande bild, ".. gifves det knappast något område af folkets dagliga lif, hvilket man ej i samlingen finner upplysande illustrationer». Men han är också noga med att betona att denna bild «af folkets dagliga lif" kan skifta inom den geografiska ram, som etnografiska utställningar genom att använda beteckningar som «indiska föremål» - normalt använde:

Naturligtvis gäller detta dock blott om de trakter, Bengalen, nordvestra provinserna, Punjab och nordvästra Rajputana, där mera planmässiga samlingar kunde göras. Riktigast och mest upplysande vore naturligtvis att skilja på de olika härkomstområdena, men i den nuvarande lokalen är detta tyvärr omöjligt: Det har därföre varit nödvändigt att slå tillsammans föremålen i större grupper. I en annan lokal och i synnerhet om vi kunde få parallelsamlingar från mellersta och södra Indien, borde dock en sådan lokal gruppering konsekvent genomföras.

Samma anmärkning kan göras beträffande de i nästa sal uppställda föremålen tillhörande religionen eller rättare sagt religionerna. Hvad norra Indien beträffar, är dock olägenheten mindre än på det profana området, ty här herskar en ganska stor uniformitet hela Gangesområdet utefter. (Stolpe 1895a:168)

Stolpes geografiska utställningsprincip gällde således inte bara länder eller folk utan också snävare regioner, om omständigheterna tillät en särskiljning på denna grund. Den påminner om den princip, som kännetecknade utställningar på Skansen och i Nordiska Museet, där folkets dagliga liv betonades och särskildes för olika landskap eller regioner. Det är sannolikt att det i denna modell finns ytterligare en svensk källa till Stolpes starka betoning av en geografiska indelning, (förutom avståndstagandet till Rudbeckianismen och Montelius regionalt förankrade arkeologi, som redan berörts). ${ }^{4}$ Åtminstone utgjorde Hazelius gärning ett inspirerande exempel i utställningssammanhang.

För att förstå Hazelius betydelse för Stolpe är det först nödvändigt att säga något om förhållandet mellan folkloristik och antropologi under Stolpes tid. Brittiska antropologer och folklorister såg ett nära samband mellan den europeiska allmogen och "primitiva folk». Edward B. Tylor och i dennes efterföljd Andrew Lang representerade en syn som fick ett domi- 
nerande inflytande inom brittisk folkloristik under slutet av 1800-talet och början av 1900-talet, där allmogens seder och bruk sågs som kvarlevor från tidigare epoker av mänsklighetens utveckling:

In savage life all these things are extant, not as survivals but as actual portions of the prevalent state of society. (Gomme 1879 citerad i Dorson 1968:223).

Inom folkloristiken kunde man leta sig tillbaka till ursprungliga primitiva föreställningar och för detta ändamål jämfördes allmogens föreställningar med dem hos primitiva folk, där förlagan kunde iakttas. För att detta jämförande projekt skulle vara trovärdigt postulerades ett nära mentalt samband mellan allmoge och "primitiva folk» och att den europeiska allmogens föreställningar varit relativt konstanta genom århundraden och till och med årtusenden. Detta innebar att skillnaden mellan primitiva folk och bondebefolkningen betraktades som näst intill försumbar. Enligt Tylor var det «scarce a hand's breadth of difference between an English ploughman and a negro of Africa» (Tylor 1871 citerat från Dorson 1968:194) och Frazer skriver i den tredje utgåvan av The Golden Bough (1911-15)

The truth seems to be that to this day the peasant remains a pagan at heart; his civilization is merely a thin veneer which the hard knocks of life soon abrade, exposing the solid core of paganism and savagery below (citerat ur Ackerman 1990:252).

Liknande formuleringar finns i överflöd inom denna folkloristiska skola. ${ }^{5}$

Jämförelser mellan "primitiva folk» och allmoge skedde således inom ramen för den brittiska antropologi som med utgångspunkt från liknande företeelser skapade evolutionistiska samband mellan i tid och rum vitt skilda folk. Stolpe tillbakavisade sådana jämförelser både för sin teori om ornamentiken och för utställningar, medan däremot Hazelius regionalt inriktade folkloristik överensstämde med Stolpes idéer. Det låg därför nära till hands för Stolpe att låta sig inspireras av Hazelius utställningsidéer och det finns också belägg för att han i denne såg ett efterföljansvärt exempel också för etnografiska museer.

Hazelius nationalromantiska intresse för svensk allmogekultur fick sitt första museala uttryck 1873 i den skandinavisk-etnografiska utställningen. I utställningskatalogen till den första etnografiska utställning som Stolpe arrangerade 1878-79 anknyter han direkt till denna utställning:

Utställningens hufvudsyfte, att väcka intresse för bildandet af ett allmänt etnografiskt museum, som skulle kunna, i jemnbredd med den af allmänheten så nitiskt och välförttjent omhuldade skandinavisketnografiska samlingen, lemna en åskådlig bild af seder och bruk hos jordens folk och utgöra en källa för vetenskapliga studier af mensklighetens kulturutveckling...(Stolpe1880:VI-VII)

I samma katalog verkar det som om han vid denna tid inte var främmande för att $\mathrm{i}$ utställningen också ta med europeiska föremål under rubriken «allmän etnografi»:

De insända bidrag, som leda sitt ursprung från de europeiska folken, voro så ytterst fåtaliga, att det var omöjligt att af dem bilda någon särskild afdelning, hvarföre de ej blifvit utställda och ej heller i denna förteckning införda. (Stolpe 1880:III). 
I sin artikel från 1903 anger han att ett etnografiskt museum "af rent praktiska skäl» måste begränsa sig till de «utomeuropeiska folken", men här markerar han också en tydlig diskontinuitet mellan folkloristik och antropologi från en mer teoretisk utgångspunkt:

De europeiska folkens etnografi, som måste behandlas efter en helt annan måttstock, har man öfverlåtit åt hvarje särskildt land att genom specialmuseer illustrera. Vi hafva $\mathrm{i}$ detta afseende gått $\mathrm{i}$ spetsen genom vårt berömda Nordiska Museum. (Stolpe 1903:455)

Stolpes åsikt att olika måttstockar gäller för etnografiska och folkloristiska museer markerade en klart avvikande hållning från folklorister, som inspirerade av Tylor, såg ett nära samband mellan "primitiva folk» och den europeiska allmogen. Även om ett sådant uttalande också verkar utesluta direkta jämförelser med den allmogekultur Hazelius ställer ut, berör inte detta den geografiska princip som Stolpe och Hazelius var överens om. Under alla omständigheter låg jämförelser med Hazelius utställningar inte så långt borta när det gäller utställningen av de indiska föremålen - där Stolpe förordar en mer "landskapsinriktad» geografisk uppdelning - eftersom indierna knappast kunde klassificeras som ett "primitivt folk». De folkliga "genomsnittsföreställningar" som han strävade efter att spegla genom föremål, stod sannolikt för en sorts allmogekultur också i det indiska fallet.

Stolpes ambition att genom föremål illustrera alla aspekter av de olika folkens liv, påverkade såväl urvalet av de föremål som han hade möjlighet att själv samla och sättet att ställa ut. I utställningarna placerades föremålen ofta i glasmontrar 97 eller på väggarna och ordnades tematiskt med hänsyn till härkomst $\mathrm{i}$ form som exempelvis indiska musikinstrument [bild 1]. Men i vissa fall arrangerades kontextuella utställningar, där en specifik miljö återskapades bland annat med hjälp av naturtrogna människomodeller («mannequin»). Några av dessa kontextuella utställningar förekommer på vykort utgivna av museet och tre av de sex illustrationerna i Stolpes artikel från 1903, där han presenterar utställningarna, ger exempel på sådana från Japanutställningen [bild 2]. Också här bör Hazelius kontextualiserade utställningar, som de exempelvis presenterades på Skansen, ha varit en inspirationskälla. Under alla omständigheter innebar denna utställningsmodell att principen om geografisk härkomst gavs en form, som klart skilde sig från typologiska utställningar, där jämförelser gjordes på grundval av föremålens funktion eller form. Inom ramen för geografisk härkomst, rymdes de få utställningsexemplen på Stolpes egen typologiska teori om ornamentiken, medan utställningar som byggde på kontextualiserade miljöer omöjliggjorde alla typologiska ansatser.

Stolpe kontextualiserade sina utställningar också $\mathrm{i}$ en annan mening. Den visuella delen kompletterades med utförlig kataloginformation, där en mängd fakta tillfördes. Även om han ofta beklagade sig över att denna kataloginformation var otillräcklig och att utförligare kataloger måste skrivas så småningom, utvecklade sig denna information ofta nog till små essäer, som också kunde läsas utan tillgång till utställningarna. Presentationen av utställningarna från 1895, ger flera exempel på detta och är mycket utförlig när det 
Claes Hallgren

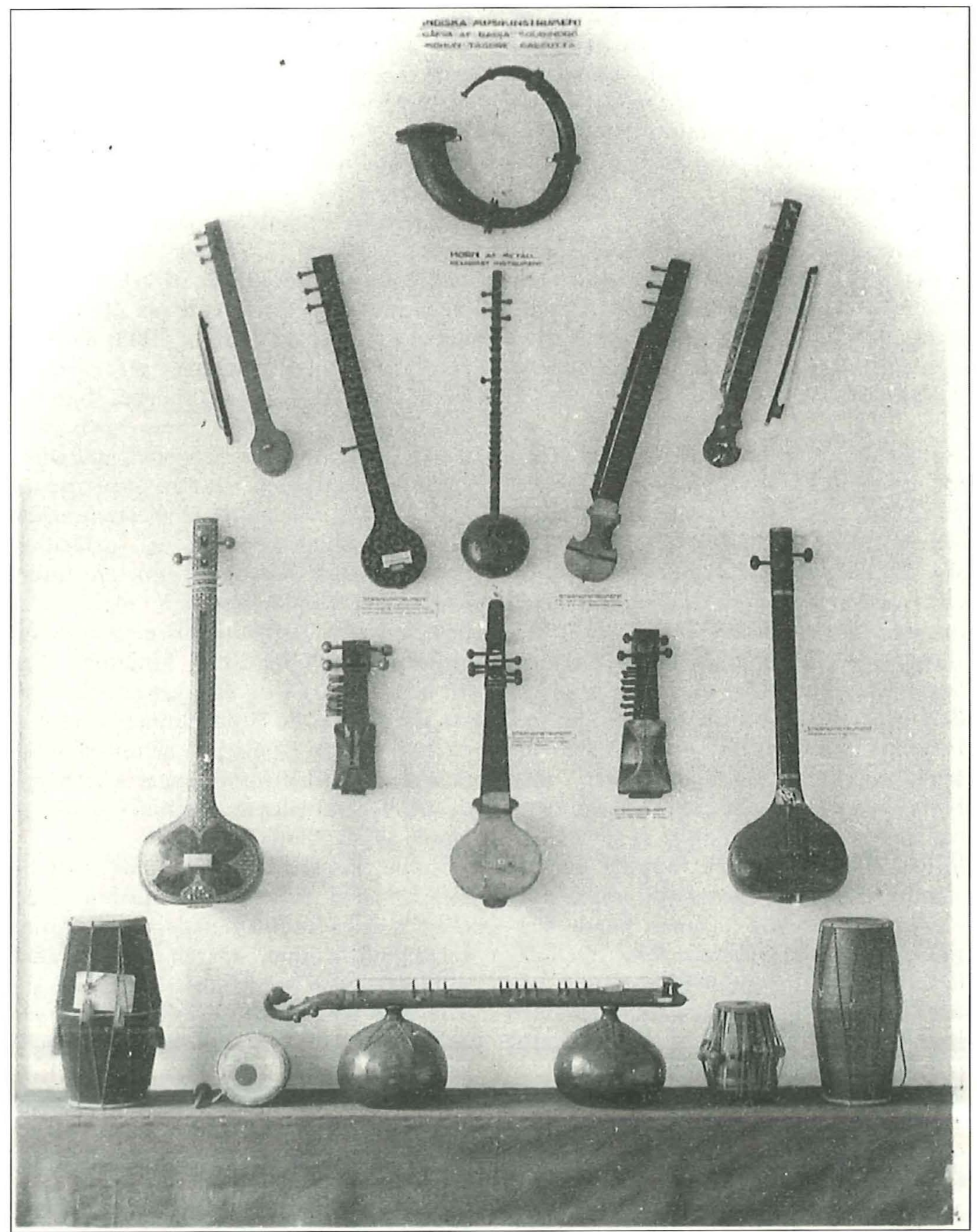


gäller de kinesiska och japanska utställningarna (Stolpe 1895a:133-142,145-159). Ett kort avsnitt där Stolpe behandlar lindade fötter i Kina kan ge en föreställning om Stolpes textmässiga kontextualisering:
Då så många missuppfattningar af detta bruk visat sig råda, torde vara lämpligt att redogöra för hvad man i detta ämne verkligen känner.

Bruket att i den tidigare barndomen så sammanpressa kvinnornas fötter att deras form helt och hål-

Till vänster: Bild 1, indiske musikinstrument, exempel på Stolpes utställningar. Foto efter vykort utgivet vid "Riksmuseets Etnografiska Afdelning". Nedan: Bild 2, "Paviljong för teceremonien». Från Japanutställningen, exempel pà Stolpes kontextuella utställningar. Foto: Folkens Museum Etnografiska.

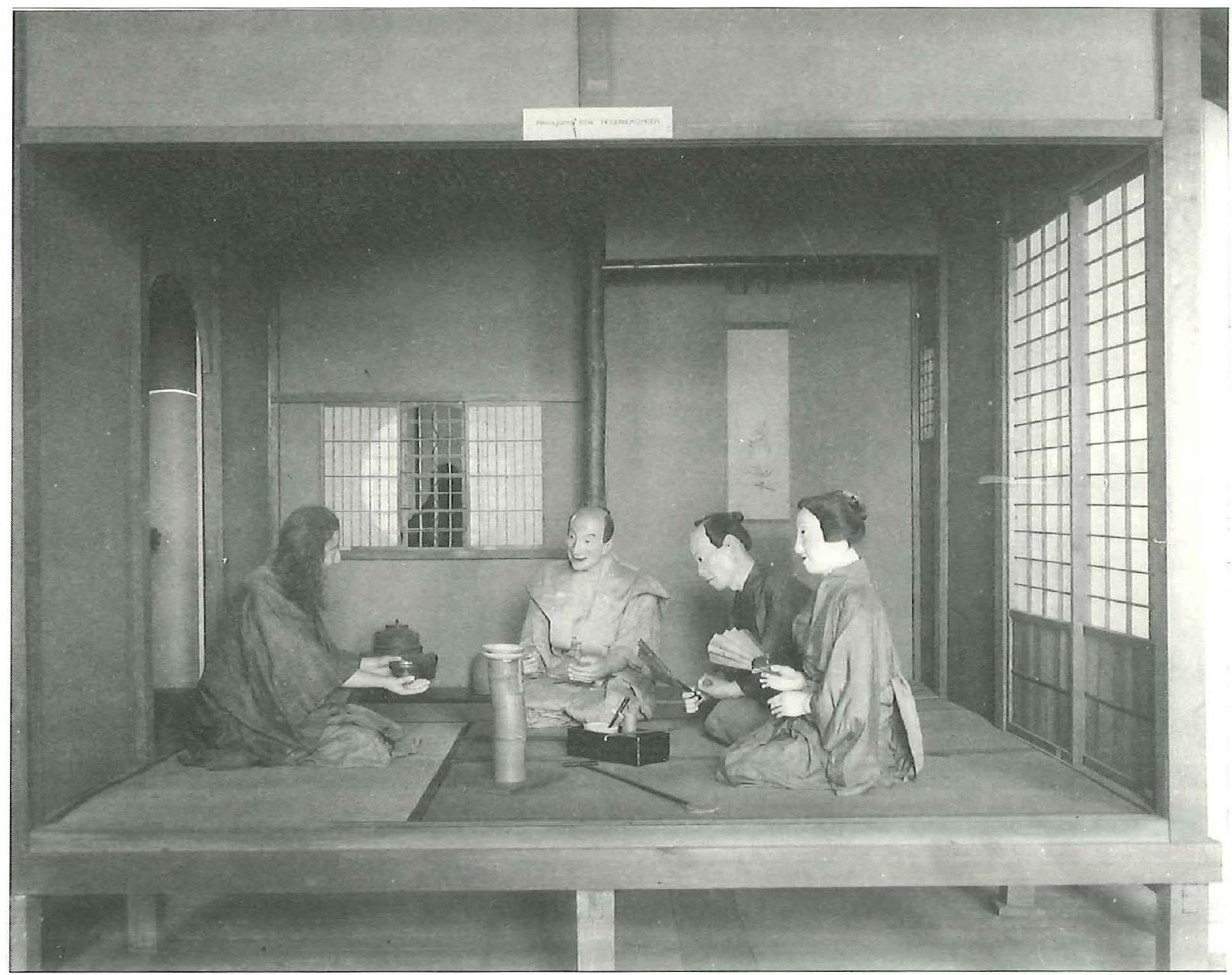


100 let omgestaltas och tillväxten hindras, är inskränkt till det egentliga kinesiska folket och förekommer icke hos de herskande mandschuerna. Ingen viss ålder är föreskrifven, då hoppressningen skall taga sin början. I förmögnare familjer sker det redan innan flickan fyllt fem år, i andra först vid hennes förlofning d.v.s. vid sju eller åtta års ålder. (Stolpe 1895a:134)

Skildringen fortsätter med ytterligare upplysningar, som täcker ungefär en sida i artikeln. Stolpe såg denna typ av kataloginformation som ett nödvändigt komplement till utställningarna. Den var en del av museets folkbildande uppgift, där allmänheten skulle «lära något om folken». I denna anda skriver han:

Kunde dessa anteckningar leda till att samlingen blefve flitigare besökt, särskildt af den studerande ungdomen, för hvilken den borde vara ett välkommet åskådningsmaterial vid sidan af den geografiska undervisningskursen, så vore ett af hufvudändamålen med dem vunnet. (Stolpe 1895a:178)

Även när det gällde vardagsföremål kunde en katalogtext,

...visa, att mången gång äfven till utseendet obetydliga föremål äro i stånd att gifva en djupare inblick i ett folks kulturlif. (Ibid:178)

Om allmänheten kunde förledas att "tro på paralleler, der sådana icke finns», av typologiskt ordnade utställningar, som jämförde liknande företeelser hos vitt skilda folk, så hade å andra sidan geografiskt ordnade utställningar nackdelen att enbart en bråkdel av "folkens seder och bruk" kunde presenteras visuellt i en utställning. (När det gällde visuell information var typologiska utställningar överlägsna efter- som föremålen så att säga berättade sin egen historia när de jämfördes med varandra.) Det var därför viktigt för Stolpe att tillfoga en mer komplett bild genom skriftlig information, om han vill informera en bred allmänhet.

\section{STOLPE OCH BOAS SOM UTSTÄLLARE}

I sin presentation av de japanska samlingarna i artikeln från 1895 använder Stolpe begreppet "folkkarakter». Det gäller japanska rustningar och vapen, där han skriver, «...denna samling gömmer åtskilliga småsaker, som äro af stor vikt för uppfattningen af den japanska folkkarakteren.» (Stolpe 1895a:148). Men speciellt accentuerat är begreppet i samband med hans beskrivning av den japanska teceremonin. "Te-ceremonien (Cha-no-yu) är en buddhistisk företeelse af största intresse. Man kan med fog säga, att man i denna egendomliga ceremoni har hela den gamla japanska folkkarakteren in nuce." ( Stolpe1895:155). Liknande begrepp förekommer på andra ställen i Stolpes utställningspresentationer och ger dem en tysk klang, med tanke på att begreppet "Volksgeist» och "Nationalcharakter" var av så central betydelse för tysk antropologi. ${ }^{7}$ Det är också sannolikt att Stolpe hämtat begreppet "folkkarakter" från tysk antropologi, men som vi har sett, finns en liknande tankegång inbakad $\mathrm{i}$ både hans arkeologi och teori om ornamentiken, utan att detta uttryck används. I linje med Montelius idéer talar Stolpe inom arkeologin om ett "grafskicks karakteristiska egendomligheter» och han valde att studera ornamentiken i Oceaniens övärld, där varje folks «egendomliga och karakteristis- 
ka» stil framträdde, utan yttre påverkan (Stolpe 1890a:195).

Vad som ytterst kan vara tyskpåverkat eller inte i detta fall är svårt att fastställa, med tanke på det stora tyska inflytandet på svensk kultur under hela 1800-talet och i början på 1900-talet, men om Stolpes teori om ornamentiken fann genklang i den anglosaxiska världen, så verkar hans utställningsverksamhet ha stått närmare den germanska. I detta sammanhang får hans typologiska syn på ornamentiken en mycket undanskymd roll medan hans betoning på geografisk förankring ges ett egenvärde och förstärks genom utställningar av kontextualiserade miljöer och katalogtexter. Även om denna modell inte var resultatet av en direkt tysk påverkan, så ligger den i linje med den antropologiska synen i Tyskland, och det förefaller symptomatiskt att Stolpe använder begreppet "folkkarakter» just i utställningstexter. Mot denna bakgrund kan det vara belysande att jämföra Stolpe med Boas, som också förordade en geografisk utställningsmodell och som hämtade denna modell direkt från den tyska traditionen.

När Boas lämnade Tyskland i mitten av 1880-talet för att fortsätta sin antropologiska verksamhet i USA blev han tidigt involverad i museiantropologi och 1896 blev han anställd vid den etnografiska avdelningen $\mathrm{i}$ American Museum of Natural History i New York (Jacknis 1985). Tidigare hade han varit indragen $i$ en debatt med Otis T. Mason och John Wessley Powell om sättet att ställa ut etnografiska föremål. I detta fall var det de etnografiska utställningarna i U.S. National Museum i Washington (Jacknis 1985:77-83) som var utgångspunkten för diskussionen. Konfronterad med ett museum som var organiserat efter evolutionistiska och typologiska principer argumenterade Boas för en omordning efter härkomst där varje folk (i det här fallet främst olika indianfolk) presenterades var för sig. Tysk tradition företrädd av Boas ställdes mot anglosaxisk tradition representerad av Mason och Powell (Bunzl 1996:56).

Mason, som var den som i första hand förde debatten med Boas, försvarade en syn på etnografiska föremål och utställningar som utgick från en biologisk utvecklingsmodell dvs. samma grundmodell som Stolpe byggde på i sin teori om ornamentikens utveckling:

They [etnologiska fenomen] may be divided into families, genera and species. They may be studied in their several ontogenies (that is, we may watch the unfolding of each individual thing from its raw material to its finished production). They may be regarded as the products of specific evolution out of natural objects serving human wants and up to the most delicate machine performing the same function. They may be modified by their relationship, one to another, in sets, outfits, apparatus, just as the insect and flower are co-ordinately transformed. They observe the law of change under environment and geographical distribution. (Mason 1887. citerat ur Stocking 1974:61)

I konkreta termer visade de existerande utställningarna på National Museum hur mänsklighetens olika uppfinningar utvecklats med utgångspunkt från olika sätt att göra upp eld, till transportmedel, keramik- och korgarbeten och andra liknande kategorier. I ett sådant arrangemang fördes föremål från olika folk ihop inom samma kategori för att illustrera teknolo- 
102 gisk utveckling (Jacknis 1985:77). Men i Boas perspektiv kunde inte innebörden av etnografiska föremål förstås,

...outside of its surroundings, outside of other inventions of the people to whom it belongs, and outside of other phenomena affecting that people and its productions. (Jacknis 1985: 79 citerat från Boas 1887 Museums of ethnology and their classification)

Likheter baserade på form och funktion ställdes mot en kontextualiserad innebörd. En skallra fick för Boas sin mening från religiösa och mytologiska föreställningar (som skilde sig hos olika folk) och inte från att skallror hade samma utseende och samma funktion av att framkalla ett visst ljud. $^{8}$

I det här avseendet är Boas och Stolpes syn påfallande lika, eftersom Stolpe, som vi sett uttryckligen varnat för att i utställningar visa på "paralleler, der sådana icke finns». Precis som Boas menade Stolpe att etnografiska museer i första hand skulle «jemföra alla föremål från ett visst folk», för att därmed komma till insikt om «det verkligt karakteristiska» (Stolpe 1882:33). Boas och Stolpes aversion mot interregionala analogier, skapade således en gemensam geografisk syn på utställningar, där en etnografisk samling i bådas ögon skulle representera "livet" hos ett visst folk.

En metod, som Stolpe använde, för att göra detta var, som vi har sett, att skapa kontextualiserade miljöer med hjälp av verklighetstrogna modeller av människor. Hazelius, en av pionjärerna för denna utställningsform, och sannolikhet den som inspirerade Stolpe i detta fall, hade använt den redan 1873 i sin nordiska etnografiska utställning (Jacknis 1985:81), medan den i Nordamerika introducerades först på världsutställningen i Chicago 1893 (Jacknis 1985:80-81). Eftersom den låg helt i linje med Boas kontextuella utställningstänkande anammade han den till en början med stor entusiasm i American Museum of Natural History. Även om Boas så småningom insåg att den var otillräcklig i många avseenden för att skapa en illusion av verkliga förhållanden (Jacknis 1985:97-103), verkar således både Boas och Stolpe ha haft en gemensam inspiratör i Hazelius - i Boas fall sannolikt indirekt, eftersom han inte behöver ha känt till Hazelius betydelse för introduktionen av denna utställningsform, då den presenterades i Nordamerika.

Precis som Stolpe ansåg också Boas att geografiskt ordnade utställningar var otillräckliga, om de inte kompletterades med utförlig textinformation. Under sin museitid skrev Boas utställningspamfletter för att råda bot på detta, men dessutom kedjades tjocka böcker, skrivna av specialister, fast vid en del föremålsmontrar för att ge ännu utförligare information. Förutom att en del av böckerna helt enkelt blev för tunga för att fästas vid en monter, var naturligtvis ett sådant arrangemang opraktiskt, och böckerna flyttades så småningom till ett bibliotek. För Boas var emellertid text viktig för att skapa de sammanhang som hans teoretiska ståndpunkt krävde och svårigheterna att förmedla denna i utställningar var sannolikt ett av skälen till att han så småningom övergav museiantropologin för att enbart framställa sina idéer i skriven form (Jacknis 1985:103-104).

Så här långt ser det ut som om Stolpe, som var erkänd och i många fall beundrad av anglosaxiska antropologer för sina idéer 
inom ornamentiken, stod på samma sida som Boas (typologins skarpaste kritiker) när det gällde utställningsarrangemang. Den kritik, som Stolpe riktar mot PittRivers utställningar motsvarades av Boas kritik av Masons och Powells uställningssyn, och Stolpe parafraserade nästan Boas när han kritiserade analogier, där inga historiska samband kan påvisas.

\section{ANTROPOLOGISK TEORI OCH UTSTÄLLNINGAR}

Eftersom det skulle ha varit fullt möjligt för Stolpe att illustrera sin geografiskt begränsade typologiska teori inom ornamentiken också i utställningsammanhang, kan man fråga sig varför han nästan helt avstod från detta. Svaret har sannolikt att göra med att etnografiska museer, vid denna tid, både var institutioner för forskning och viktiga bildningsorgan för allmänheten. Vi har redan sett att Stolpe i samband med utställningar själv gör en skillnad mellan vetenskapliga och allmänbildande syften, och att han poängterar utställningarnas betydelse för "den allmänhet" som «söker näring för sin vetgirighet». Det framgår också att just den geografiska principen var viktig för detta ändamål, eftersom allmänheten kommer för att «få lära något om folken». Samma allmänhet skulle också förhindras att dra felaktiga slutsatser genom att se "paralleler, der sådana icke finns", dvs. samband mellan vitt skilda folk skapade på typologisk grund.

Det är denna omsorg om allmänhetens bildning som får Stolpe att i utställningssammanhang framhäva den geografiska principen. Men samma ambition, att tillfredsställa allmänhetens krav, kunde ibland ockå leda till att den geografiska modellen övergavs för en evolutionistisk modell. Just med hänsyn till detta krav planerade Boas vid åtminstone ett tillfälle en utställning, som följde en evolutionistisk modell. För att tillfredsställa besökande hantverkare, avsåg han att visa hur snickeri, smide och vävning utvecklats hos olika folk. I ett vidare evolutionistiskt perspektiv skulle utställningen illustrera hur utvecklingen gått från ett beroende av de produkter som funnits tillgängliga $\mathrm{i}$ den närliggande bomiljön, till en användning $i$ mer avancerade samhällen av material från alltmer avlägsna områden (Jacknis 1985:87). Utställningen blev aldrig genomförd, men att allmänhetens krav kunde leda till paradoxala omkastningar mellan utställningsform och teoretisk ståndpunkt, visas också av att Boas antagonister bland typologerna, Mason och Powell, någon gång kunde tillämpa den geografiska modellen, när den ansågs pedagogiskt riktig för att informera allmänheten (Jacknis 1985:80-82).

Det dubbla syfte som etnografiska museer hade, både som institutioner för forskning och som bildningsorgan för allmänheten, skapade denna paradoxala situation. Boas och Stolpe framstod som bundsförvanter i sina roller som utställare i förhållande till Mason och Powell, trots att Stolpe i sina typologiska resonemang inom ornamentiken stod närmare Mason och Powell än Boas, medan Mason/Powell och Boas till och med kunde växla teoretiska positioner med varandra i sina verksamheter som utställare.

Det fanns inget enkelt samband mellan antropologisk teori och utställningar. I vissa fall kunde utställningsformen vara ett direkt uttryck för en teoretisk syn, 
104 medan den i andra fall var en anpassning till vad man betraktade som allmänhetens kunskapskrav. Stolpes teori inom ornamentiken lämpade sig väl $\mathrm{i}$ vetenskapliga sammanhang, medan den däremot inte lika väl kunde presenteras $\mathrm{i}$ utställningar riktade till allmänheten. För Boas gällde det motsatta förhållandet. Trots exemplet där han förordar en evolutionistisk modell för att tillmötesgå allmänheten, var den kontextuella utställningsmodell som han normalt företrädde helt i linje med den teoretiska syn som hans kritik av evolutionismen ledde fram till, där varje kulturs egenvärde framhävdes. I sin polemik med Mason skriver Boas:

It is my opinion that the main object of ethnological collections should be the dissemination of the fact that civilization is not something absolute, but that it is relative, and that our ideas and conceptions are true only so far as our civilization goes. I believe that this object can be accomplished only by the tribal arrangement of collections. (Boas 1887 citerat ur Stocking 1974:66)

Detta uttalande är i komprimerad form en programförklaring av den kulturrelativistiska syn som kom att prägla Boas framtida antropologiska gärning, sedan han lämnat utställningsverksamheten bakom sig. Men den formuleras här som ett utställningskoncept, och visar på den samstämmighet, som Boas såg mellan utställningsarrangemang och sin mer allmänt formulerade antropologiska teori.

\section{NATURLAGAR OCH KULTURRELATIVISM}

De likheter man finner mellan Boas och Stolpes ståndpunkter när det gäller utställningar riskerar att dölja de teoretiska motsättningar som fanns mellan dem. Trots sina kontextuella utställningar övergav eller modifierade inte Stolpe den darwinistiskt inspirerade evolutionism, som låg till grund för hans teori om ornamentiken. Även om denna evolutionism inte syntes direkt $\mathrm{i}$ hans utställningar, visar hans presentation av utställningarna i Hvar 8 Dag 1903 att den också finns med i detta sammanhang.

Artikeln innehåller, som man kan vänta, en del allmänna formuleringar i evolutionistisk anda. Stolpe menar t.ex. att ett etnografiskt museum ska visa den intellektuella utvecklingen «från de lägre ståendes vidskepelse och trolldom, upp till de mera framskridnas mer eller mindre högt utvecklade religioner» och att det är "den mänskliga kulturens utvecklingshistoria, som man finner framställd i de etnografiska museerna» (Stolpe1903:455). Sådana uttalanden var emellertid knappast av avgörande teoretisk betydelse, eftersom de, i en period dominerad av evolutionistiskt tänkande nästan tillhörde det allmänna språkbruket i etnografiska sammanhang. Liknande formuleringar kan man också hitta hos Boas vid denna tid, som exempelvis skriver

...even the poorest tribe, the degraded criminal, and the physical degenerate [are] worthy of attentive study, because the expression of his mental life, no less than his physical appearance, may throw light upon the history of mankind. (Boas 1904 citerat ur Stocking 1974:34). 
Ändå är det alldeles uppenbart att Stolpe i motsats till Boas ser sin geografiska utställningsmodell i ljuset av ett evolutionistiskt ramverk. Stolpes avslutning av artikeln avslöjar detta tydligt och på ett uttalat teoretiskt sätt:

Det kan väl hända att någon kan tänka: men tjänar det verkligen något till att studera de lägre, ja de lägst stående folken? är något däraf att lära? - Ja! mycket! lika visst som hela vår nuvarande andliga egendom är resultatet af en genom årtusenden gående utveckling, lika visst är, att denna utveckling ej kan rätt förstås, utan att man i grund känner äfven de primitiva stadierna på mänsklighetens långsamt trampade väg framåt. Det gör ett egendomligt intryck att hos folk, som ej stått i nämnvärd beröring med någon högre kultur, igenkänna sådana fullkomligt själfständiga tankar och idéer som vi skulle vara böjda att tro födda igår hos något af de högre kulturfolken. Den "primitiva" människan är ej på långt när så primitiv som hon vanligen tros vara. Äfven hon har bakom sig en oändlig lång utveckling, styrd af samma naturlagar som ledt vår egen. Detta är en af de många lärdomar, som stå att hämta ur studiet af de primitiva folkens alster, på hvilka alla hon satt prägeln af sitt säregna skaparlynne och af de yttre förhållanden, under hvilka hon lefver. (Stolpe1903:459)

Stolpes hänvisning till de för alla människor gemensamma «naturlagar» som styrt utvecklingen är speciellt talande. Dels utgör de en länk till de naturlagar som han menade låg bakom ornamentikens utveckling och dels står de i bjärt kontrast till Boas åsikt att våra idéer och begrepp enbart är sanna för vår egen civilisation. För Stolpe förblev antropologin "absolut» i naturvetenskaplig mening och underordnad samma evolutionistiska utveckling som gällde inom biologi och zoologi.
Stolpe modifierar denna vision något genom att nämna att ett "säreget skaparlynne» hos de olika folken ändå existerar, vilket kan ses som ett länk till Boas kulturspecifika syn. Boas, å sin sida, var i början av sin karriär inte främmande för tanken på en lagbunden utveckling, men han menade han att en sådan måste påvisas utifrån induktiv kunskap i linje med en dominerande syn inom tysk antropologi. Det var först när vi hade faktiskt grundad eller historiskt korrekt kunskap om olika folk, som vi kunde fastställa universella lagar för utvecklingen. Vetenskapens första uppgift var att samla sådan kunskap för att $\mathrm{i}$ nästa skede visa på de övergripande sambanden:

We are still searching for the laws that govern the growth of human culture, of human thought, but we recognize the fact that before we seek what is common to all culture, we must analyze each culture by careful and exact methods... (Boas 1898 citerat ur Stocking 1974:108)

I praktiken var det naturligtvis omöjligt att på detta sätt fastställa universella lagar, och Boas kom därför att alltmer betona att varje kultur måste ses som sammanhållna enheter som inte kunde bedömas utifrån någon universell måttstock. Att framställa deras "säregna skaparlynne» eller med Boas egna ord deras "genius», som "Volksgeist» översattes till i hans engelska texter, blev därför antropologins uppgift.

Stolpe gick den motsatta vägen genom att förutsätta att fastställda universella lagar för utveckling existerade och att det var antropologens uppgift att kartlägga dessa. Inom ramen för en sådan utveckling rymdes dock ett «skaparlynne», som 
åtminstone i utställningssammanhang gick Boas något till mötes. Som vi har sett var Stolpe inte heller främmande för att i utställningssammanhang anknyta till det tyska begreppet «folkkaraktär».

Det är naturligtvis inte uteslutet att Stolpe under olika skeden av sin utställningsverksamhet kom att lägga olika vikt vid förhållandet mellan en specifik geografisk identitet och en lagbunden evolution. Ingen av de tidigare museipresentationerna har en så uttalad evolutionistisk grundsyn som texten från 1903. I tidigare presentationer är, som vi sett, likheten mellan Stolpes och Boas syn många gånger påfallande. Det är svårt att avgöra om detta står för en vacklande teoretisk inställning hos Stolpe. Ingenting tyder emellertid på att han mot slutet av sitt liv var på väg att modifiera den naturvetenskapliga syn som en gång förde honom in på arkeologins och antropologins område. De «naturlagar» som i början av karriären fick honom att argumentera för «ornamentens biologi» åberopas också i utställningssammanhang i en av hans sista skrifter, två år före hans död.

Det fanns emellertid andra skäl, än en vacklande teoretisk inställning, till att Stolpe i sin roll som utställare och folkbildare kom att accentuera en kontextuell syn på utomeuropeiska folk, som i väsentliga avseenden låg mycket nära Boas kulturrelativistiska syn. Dessa skäl är förknippade med de tidigare berörda skillnader som kunde finnas mellan en allmän teoretisk hållning och teorier som aktualiserades i utställningsverksamhet.

Utställningsverksamheten vände sig till en annan sorts publik än teoretiska skrifter - en publik som visserligen var mindre initierad, men som ändå omfattade vissa idéer om utomeuropeiska folk, som Stolpe var mån om att vederlägga. Publiken «kommer ej till museet för att studera metkrokar eller klubbor, eller gräskjolar», skriver Stolpe. Han vänder sig här mot en äldre syn där etnografiska föremål huvudsakligen betraktades som kuriosa, utan att sättas in i något sammanhang. Och han är också, angelägen, som vi har sett, att allmänheten inte ska förledas att tro på paralleller «der sådana icke finns». För att kunna vederlägga «felaktiga» attityder i dessa avseenden hos publiken var Stolpe tvungen att betona både en kontextuell syn, där föremålen sattes in i sina rätta sammanhang, och en syn som i hög grad framhävde specifika föreställningar för olika folk.

Etnografiska föremål är redan tolkade av publiken innan de «blivit informerade» och utställaren kan därför inte välja sin teoretiska utgångspunkt oberoende av den tolkning publiken gör eller den tolkning utställaren tror att den gör. Folkbildning i detta sammanhang innebar inte för Stolpe i första hand en förenkling, utan accentuering av en viss typ av fakta, som var kongeniala med den kulturrelativistiska syn som Boas gjorde sig till tolk för.

En orsak till att Stolpe nästan helt avstod från en typologisk utställningsmodell som passade hans teori om ornamentiken var sannolikt att han i utställningsammanhang argumenterade mot helt andra "teorier» än dem han polemiserade mot i sina skrifter om ornamentiken. 


\section{NOTER}

1. Den första artikeln översattes, tillsammans med en förkortad version av den andra artikeln redan 1891-92 till engelska och 1892 till tyska. Den engelska översättningen publicerades igen 1927 tillsammans med, Studier i Amerikansk Ornamentik(1896), som då översattes för första gången.

2. Stolpe bedömde naturligtvis Rudbeck efter sin tids vetenskapliga ideal. För en nyanserad bedömning som sätter in Rudbecks idéer i ett tidssammanhang se Eriksson 1994.

3. Det saknades inte modeller för sådana, med tanke på att hela museer var organiserade efter typologiska principer - som Pitt-Rivers museet i Oxford, U.S. National Museum i Washington och ett privatmuseum i Hamburg, Goodeffroy, som upphörde redan under Stolpes livstid och som Stolpe såg som exemplariskt med utgångspunkt från sin egen vision:»Vill man se idealet för ett sådant material, må man gå till museum Godeffroy.» (Stolpe 1882:18). Eftersom Stolpe hade kunnat anpassa sådana exempel till att illustrera geografiskt begränsade serier, är det uppenbart att han medvetet valde att inte framhäva den typologiska utställningsmodellen.

4. Rolf E. Du Rietz menar att det etnografiska museet i Köpenhamn, där utställningarna var ordnade efter härstamning, spelade en stor roll för Stolpes framtida bana som etnograf och museiman:

«I Köpenhamn mötte Stolpe sitt öde/.../Stolpe blev bergtagen av samlingarna och av den nya vetenskapens möjligheter, och från och med nu såg han som sin främsta livsuppgift att verka för den etnografiska forskningen och för tillkomsten av ett svenskt etnografiskt museum. Han reste ut som arkeolog och kom hem som etnograf, vilket emellertid inte hindrade att han under många år, såsom amanuens vid Vitterhetsakademien, måste ägna en betydande del av sin tid åt arkeologiska arbetsuppgifter.» (Du Rietz1984:13)

Stolpe var visserligen en beundrare av museet $\mathrm{i}$ Köpenhamn (Stolpe1882:5-6), men jag har inte funnit något som ger belägg för att besöket 1872 skulle ha det avgörande inflytande för Stolpes etnografiska gärning, som Du Rietz menar att det hade. Han anger ingen källa för sitt påstående, men det får ett visst stöd av Retzius $\mathrm{i}$ hans minnesskrift efter Stolpes död, där han skriver «Jag erinrar mig ännu med hvilken entusiasm han efter hemkomsten från Kjöbenhavn talade om dess etnografiska samlingar och i allmänhet om den etnografiska vetenskapens höga uppgifter.»(Retzius 1905:7) - ett påstående som möjligen är påverkat av att Retzius tar åt sig äran av att ha väckt Stolpes intresse för etnografi (ibid:6). Stolpes omfattande arkeologiska verksamhet efter 1872, kan emellertid knappast betraktas som ett "måste», som Du Rietz gör. Det är också svårt att tänka sig att Stolpe «reste ut som arkeolog och kom hem som etnograf" med tanke på det nära samband som fanns mellan arkeologi och etnografi under Stolpes tid. När Stolpe korresponderar med Charles Hercules Read vid British Museum om sin medverkan vid British Associations möte i Liverpool 1896, framgår det att Stolpe ämnade tala om de arkeologiska Vendelfynden. Read, som beundrade Stolpes etnografiska insats inom ornamentiken, har svårt att dölja sin besvikelse "I think your Vendelfind would do very well for the visit/.../but the ornamental development would have done equally well» (Brev 30 juni 1896). Trots sin ställning inom brittisk antropologi på grund av teorin om ornamentikens utveckling, väljer således Stolpe att framträda med ett arkeologiskt föredrag. Det finns även direkta belägg för att Stolpe motsatte sig en åtskillnad mellan etnografi och arkeologi. I en artikel om de etnografiska samlingarna i

Kristiania skriver han: «Man får någon gång höra, att de försvunna kulturformerna ej hafva något med etnografien att 
108 skaffa. De tillhöra arkeologien, säger man. Jag får tillägga, att jag dock aldrig hört någon verklig etnograf drifva denna egendomliga sats. Ingen verklig arkeolog förnekar, att hans arbete ytterst går ut på etnografiska resultat.» (Stolpe1890b:62)

5. För sambandet mellan antropologi och folkloristik se Dorson 1968:187-441 och Ackerman 1990: 81-82, 85,170-171, 211, 249, 252)

6. Betydelsen för Stolpe av Hazelius regionalt inriktade folkloristiska utställningar, accentueras av att det faktiskt fanns ett folkloristiskt museum i Sverige, Kulturen i Lund, med typologiskt inriktade samlingar. Med tanke på Stolpes intresse för typologi inom ornamentiken kan det verka egendomligt att detta museum inte framhölls som ett inspirerande exempel. På typologisk grund jämfördes där svenska folkloristiska föremål med utländska föremål, inkluderande vad vi idag skulle kalla etnografiska föremål. Detta gjordes utifrån samma utvecklingsfilsofi som likställde utvecklingen hos växter och djur med typologisk utveckling hos föremål - d.v.s. utifrån samma «biologiska» modell som kännetecknade Stolpes teori om ornamentiken, men utan det strikt "genetiska» samband mellan utvecklingsformer, som i Stolpes ögon var av fundamental betydelse för att härleda en sådan utveckling.

Så här formulerar sig ordföranden i Kulturens styrelse i ett tal 1907:

«De mänskliga redskapen och konstalstren framträda icke isolerade utan som länkar uti en utvecklingskedja. De framstå vid närmare betraktelse som frukter av en evolution, påminnande om den som frambragt de olika arterna i växt- och djurvärlden. Det är en stor vetenskaplig uppgift att påvisa denna utvecklingshistoria. Vårt museum försöker fylla den uppgiften genom att ordna föremål i typologiska serier vart och ett efter sin art.

Men länkarna i dessa serier finnas ej fulltaliga inom eget land. Ej sällan har en typ utvecklat sig utomlands och först senare kommit till oss. Detta förklarar varför muséet rymmer så många föremål av främmande ursprung. De flesta av dessa utländska ting stå i släktskapsförhållande till motsvarande svenska. De hava vanligen varit mönster och förebilder för de senare och försvara sålunda väl sin plats i detta den svenska kulturens museum, om ett sådan försvar eljest behövs. Museets grundare Georg Karlin åberopar detta tal i sina tryckta vägvisare till museet, vilket understryker att det rörde sig om en av de grundläggande principerna för museet.» (Landberg 1994:34).

7. I en introduktion, sannolikt skriven av C.V. Hartman, till Ida Trotzigs bok om den japanska teceremonin (Trotzig 1911) används uttryckligen begreppet "folksjäl». Ida Trotzigs intresse för teceremonin inspirerades ursprungligen av Stolpes beskrivning av den och det förfaller uppenbart att också introduktionsförfattaren anspelar på Stolpes verk när han associerar teceremonin med japanernas folksjäl.

8. Förutom Masons och Powells rent teoretiska invändningarna mot en sådan utställningsmodell, där mänsklighetens utveckling inte kunde skönjas på ett tydligt sätt, ansågs också en modell baserad på härstamning ta för mycket plats och kosta för mycket. Ur utställningssynpunkt hade den nackdelen att ta stora utrymmen i anspråk. Istället för att låta en pilbåge och pil illustrerade en viss utvecklingsnivå skulle man vara tvungen att anskaffa liknande pilbågar och pilar för alla de indianfolk som figurerade på utställningen.

\section{LITTERATURLISTA}

Ackerman R. 1987, 1990. J.G. Frazer. His Life and Work. Cambridge: Cambridge Univ. Press

Boas F. 1927,1955. Primitive Art. New York: Dover Publications.

Bunzl M. 1996. Franz Boas and the Humboldtian 
Tradition. From Volksgeist and

Nationalcharakter to an Anthropological

Concept of Culture. i G.W. Stocking (ed.),

London: The Univ. of Wisconsin Press.

Chapman W.R. 1985. Arranging Ethnology:

A.H.L.F. Pitt Rivers ans the Typological

Tradition. i G.W. Stocking (ed.), Objects and

Others. Essays on Museums and Material Culture.

London: The Univ. of Wisconsin Press.

Jacknis I. 1985. Franz Boas and Exhibits: On the

Limitations of the Museum Method of

Anthropology. i G.W. Stocking (ed.), Objects and

Others. Essays on Museums and Material Culture.

London: The Univ. of Wisconsin Press.

Dorson R.M. 1968. The British Folklorists. A

History. London: Routledge \& Kegan Paul.

Du Rietz R.E. 1984. Hjalmar Stolpe och Etnografins

Framväxt $i$ Sverige. $i$ Resa med Vanadis.

Utställningskatalog. Etnografiska Museet.

Eriksson G. 1994. The Atlantic Vision. Olaus

Rudbeck and Baroque Science. Science History publications/USA.

Landberg A. 1994. Kulturen och Världskulturen. i Världskulturen. Arsbok Kulturen. Lund.

Nordenskiöld E. 1907. Kortfattad handledning för Besökande af Riksmuseets Etnografiska Afdelning 1. Utställningskatalog.

Retzius G. 1905. Hjalmar Stolpe. Ymer.

Stocking, G.W. 1974. The Shaping of American Anthropology, 1883-1911. A Franz Boas Reader. New York: Basic Books, Inc.

Stocking, G.W. 1987,1991. Victorian Anthropology. New York: The Free Press Macmillan.

Stolpe H. 1880. Den Allmänna Etnografiska Utställningen 1878-1879. II. Special.Förteckning. Stockholm

Stolpe H. 1882. Nagra ord om de etnografiska museerna $i$ Europa, deras nuvarande ställning och deras framtidsutsigter. Stockholm.

Stolpe H. 1890a. Utvecklingsföreteelser i naturfolkens ornamentik. Ymer.

Stolpe H. 1890b. Om Kristianias universitets etno- grafiska samling. Ymer.

Stolpe H. 1891. Utvecklingsföreteelser i naturfolkens ornamentik II. Ymer.

Stolpe, H. 1895a. Om Vårt Etnografiska Museum. Särskildt om dess Afdelning II. Ymer.

Stolpe, H. 1895b. Tuna-fyndet. Ymer.

Stolpe H. (1896. Studier i Amerikansk

Ornamentik. Ett Bidrag till ornamentens Biologi. Stockholm.) övers. 1927. Studies in American

Ornamentation. A contribution to the Biology of

Ornament. in H. Stolpe, Collected Essays in

Ornamental Art. Stockholm.

Stolpe H. 1903. Hvad är och Hvad bör ett

Etnografiskt Museum vara? HVAR 8 DAG, 19

April.

Trigger B.G. 1989. A History of Archaeological

Thought. Cambridge: Cambridge Univ. Press.

Trotzig 1911. Cha-No-Yu. Japanernas Teceremon

\section{SUMMARY \\ Hjalmar Stolpe (1841-1905) \\ ethnographer and.curator}

The paper portrays Hjalmar Stolpe (1841-1905), a Swedish archæologist and ethnographer, best known for his excavations of Birka, the famous Viking Age site west of Stockholm. He is less known as an ethnographer although his research on the development of ornamentation has gained some international recognition. His ambition to popularize ethnography in exhibitions is the focus of the paper.

His contemporary, the anthropologist Franz Boas (1858-1942), conceived his exhibitions in accordance with his theories; in contrast Stolpe did not try to communicate the result of his own research in the exhibitions. Instead, like Boas, he wanted to illustrate the cultures in limited areas - not to bring out the similarities of widely separated cultures, but to indicate their individual character which was in 
Claes Hallgren

110 fact also the basis of his own research on ornamentation.

However his general theory of culture was influenced by Darwin and he tried to show the gradual refinement in historical sequences of ornaments. Of course this was incompatible with Boas' ideas and consequently in his work on primitive art Boas criticised Stolpe's view.

In practice, as a producer of exhibitions, he wanted however to counteract the popular belief in a universal law of development in all human cultures. Every region or people should be understood in its own context.

In Stolpe's day as well as nowadays anthropological theory is difficult to translate into exhibitions. The case of Hjalmar Stolpe illustrates clearly this still current problem in ethnographic museums.

Claes Hallgren, FD, arbetar med ett forskningsprojekt knutet till Folkens Museum, Stocxkholm. Adr: Skainegatan 68 A, S-116 37 Stockholm e-mail:xfa153c@tninent.se 